\title{
L1 Language Experience and English Phonological Awareness of Chinese College Students*
}

\author{
Min $\mathrm{Hu}$ \\ Southwest University of Political Science \& Law, Chongqing, China
}

\begin{abstract}
This study investigates the roles of two kinds of L1 language experience - early spoken language acquired before literacy and used as home language as well as Pinyin alphabetic knowledge-in Chinese college students' phonological awareness (PA) in English. PA is critical to the improvement of language skills in either L1 or L2. Research on contributing factors for PA performance can provide language teachers with guidance on enhancing their students' PA. A questionnaire was conducted to examine 408 adult participants' home language. A Mandarin PA test, which included syllable differentiation, onset oddity, rhyme oddity and tone identification, was used to assess their Pinyin alphabetic knowledge. An English PA test was carried out to assess three levels of PA (syllable, onset-rhyme and phoneme) across four tasks (oddity, segmentation, blending and substitution). Results show that 1 ) these two kinds of L1 language experience exerted significant effects on adult learners' PA in English; 2) the effects were modified by both level of PA and difficulty of task; and 3) the effects appeared weak due possibly to adult learners' higher English proficiency. These results underscore the necessity to consider the impact of $\mathrm{L} 1$ language experience in both researching and training Chinese learners' PA in English.
\end{abstract}

Index Terms — phonological awareness, early spoken language, pinyin, alphabetic knowledge, EFL

\section{INTRODUCTION}

Phonological awareness (PA) is "an individual's awareness of the sound structure, or phonological structure, of a spoken word" (Gillon, 2004, p. 2) and specifically denotes the ability to not only detect but analyze internal segments of words (Liberman, Shankweiler, Fisher \& Carter, 1974; Morais, Alegria, \& Content 1987; Morais, Cary, Alegria \& Bertelson, 1979). Based on the linguistic status hypothesis (Treiman \& Zukowsik, 1996), PA is a three-level ability which includes the higher level of syllable awareness, middle level of onset-rhyme awareness and lower level of phoneme awareness. Research evidence has established PA as a potent facilitator for reading in either L1 or L2 (e.g., Liberman, Shankweiler \& Liberman, 1989; Stanovich, 1992).

In terms of EFL learners in Mainland China, the development of PA in English fosters their English skills. Learners' lack of PA training at various stages of English learning is a prevailing phenomenon because Chinese English teachers know little about PA's critical role in English learning (Ding \& Peng, 1998). Although recent years have witnessed considerable studies on PA in English of Chinese learners, most of these (e.g., Ding \& Peng, 1998; Wang, 2010) explored the predictive role of PA in spelling and reading instead of factors facilitating PA development. It is the latter line of research that can provide Chinese English teachers with guiding principles for their design of PA teaching. This line of research (e.g., Holm \& Dodd, 1996), however, was primarily conducted in an ESL learning environment and thus the findings cannot be applied to an EFL learning context. As for those few studies (e.g., Pan, 2012; Zhang \& Lin, 2002; Zhu, 2014) on factors affecting Chinese EFL learners' PA, three limitations attract attention: 1) ignoring adult learners, 2) mainly examining nonlinguistic factors and 3) investigating only one factor in a single study.

Accordingly, this study aims to investigate mixed contributing factors for all levels of PA in English to provide implications on promoting Chinese EFL learners' PA in English. By centering on college learners, this study also intends to enhance the inclusiveness of literature on Chinese learners' PA in English.

\section{LITERATURE REVIEW}

Previous research on factors that may affect PA in various languages has demonstrated that language experience is a stronger factor than intelligence, age, tasks and so on. Two kinds of language experience have been found to play a major role in L1 PA improvement: early spoken language acquired prior to alphabetic literacy and alphabetic knowledge gained from reading instruction or training on alphabetic principles. PA skills in L1 developing as a result of the above language experience can then transfer to improve PA in L2.

\footnotetext{
* Supported by the Youth Project of Humanities and Social Sciences by the Ministry of Education of PRC (13YJC740031) and by Southwest University of Political Science \& Law (2013-XZRCXM006).
} 


\section{A. Early Spoken Language}

Caravolas and Bruck (1993) suggest that before literacy education, children's PA development is influenced by phonological features of their L1. Echoing them, Goswami (1999, p. 139) posits that "differences in the phonological input provided by different languages should affect the development of children's awareness of the different phonological levels". Anthony and Francis (2005, p. 256) specify these differences as a "number of determinants of the linguistic complexity of a spoken language-e.g., saliency and complexity of word structures, phoneme position, and articulatory factors". Consequently, these differences cause language-specific patterns to emerge in PA development of preliterate children speaking different languages. Evidence emanates from studies which compared English-speaking children with those speaking other languages.

Children who spoke Italian, Turkish and Greek were found to acquire better syllable awareness and phoneme awareness than children who spoke English (Cossu, Shankweiler, Liberman, Katz \& Tola, 1988; Demont \& Gombert, 1996; Durgunoglu \& Oney, 1999). The results were attributed to the simpler syllable structure and fewer vowels in the three languages as opposed to English. On the other hand, Cheung, Chen, Lai, Wong and Hills (2001) found that English-speaking children performed significantly better on PA tasks than Cantonese-speaking ones and reasoned that the complexity of spoken English contributed to English-speaking children's better overall PA. As shown by the Caravolas \& Bruck (1993) study, Czech-speaking children scored significantly higher on repetition of CC-V words, corresponding to saliency of double onsets in Czech while English-speaking children scored significantly higher on repetition of C-VCs, corresponding to saliency of C-VC structures in English. Bruck, Genesee and Caravolas (1997) reported that French-speaking children attained syllable awareness earlier but phoneme awareness later than their English counterparts, a result which is likely explained by saliency of a specific phonological unit in respective languages. These findings point to the effects of the linguistic complexity of oral language input on PA patterns of preliterate children.

Insufficient as it is, a growing body of research has been conducted exploring how early spoken language influences Chinese speakers' PA development in Mandarin due to their unique language environment. There are eight varieties of spoken Chinese, each of which consists of various dialects, with Northern Speech most spoken. Upon entry into elementary school, children are taught Mandarin, a language standard used as lingua franca in China with phonological and grammatical influence from Mandarin dialects (Sun, 2006). Chinese students usually speak their local dialects at home and Mandarin at school. With the Chinese government's "Speak Mandarin Nationwide" campaign, however, an increasing number of Chinese parents would rather choose Mandarin over their dialect as home language for fear that speaking the dialect would negatively affect their children's acquisition of Mandarin (Liu, 2011). Some Chinese researchers have shown their concerns by seeking to verify a positive effect of dialect on PA in Mandarin.

Such research has yielded mixed results. In the Chen et al. (2004) study, Cantonese-Mandarin bilingual children at grade two acquired significantly better PA in Mandarin than their Mandarin monolingual peers, but the dialect's facilitating effect did not occur to grade-four children. R. B. Li, Chen, Wang and Li (2011), on the contrary, reported that several groups of children who spoke different dialects of Min (a Chinese variety) all failed to score significantly higher than Mandarin monolinguals, but the study also found that the dialect's negative effect declined with reading instruction. Both Wang (2004) and Lin, Wang, Qian and Qiu (2011) reported a positive effect of dialect on PA in Mandarin for children of all ages who spoke Chinese varieties of Min or Hu. These conflicting findings demonstrate that the facilitating effect of dialect is not universal but selective (Bruck \& Genesee, 1995), depending on possible factors such as the phonological complexity of a dialect, children's literacy level or frequency of dialect use.

Given that a dialect is the early spoken language for many Chinese students, it is of particular interest to examine how this language experience would impact their PA in English. To date, there are only two relevant studies. Zhu (2014) reported that Hu-Mandarin bilingual preschoolers performed significantly worse on differentiation tasks but better on manipulation tasks than their Mandarin monolingual peers. Xu (2015) found no correlation between Chinese college students' PA in English and their Mandarin-dialect bilingualism. Therefore, more studies are called for.

\section{B. Alphabetic Knowledge}

Developmental research has provided evidence for the trajectory of different levels of PA. As Goswami and Bryant (1990) suggest, awareness of larger phonological units (syllables and rhymes) develops earlier than that of smaller phonological units (onsets and phonemes). English-speaking children have developed syllable awareness by age three (Bryant, MacLean, Bradley \& Crossland, 1990) and rhyme awareness before age four (Maclean, Bryant, \& Bradley, 1987), but their onset awareness develops around 5 years old (Barton, Miller \& Macken, 1980) and phoneme awareness will not develop until age seven (Bruce, 1964). That is, awareness of syllables and rhymes develops independently of alphabetic literacy while awareness of onsets and phonemes develops in connection with alphabetic literacy (Liberman et al., 1974; Maclean, Bryant \& Bradley, 1987; Stanovich, Cunningham \& Cramer, 1984; Yopp, 1988). The reason, as theorized by Morais et al. (1987), is that reading instruction highlights the grapheme-phoneme correspondence (GPC) of an alphabetic orthography and enhances learners' perceptions of the phonological structure at the phonemic level. Mann (1991, p. 61) extends "knowledge of an alphabetic orthography" to "experience in manipulating the internal structure of words". 
The literature has seen converging evidence from studies that compared preschoolers with beginning readers (Bowey \& Francis, 1991), children learning to read with different types of instruction (whole-word vs. phonics) (Bentin, Hammer \& Cahan, 1991) and children with and without training on phonemic manipulation (Alegria, Pignot \& Morais, 1982; Kartal, Babür \& Erçetin, 2016) as well as from studies comparing adults with and without literacy problems (Morais et al., 1979; Morais, Bertelson Cary \& Alegria., 1986). The results confirmed that onset and phoneme awareness, as opposed to syllable and rhyme awareness, do not develop naturally with cognitive growth, but are associated with alphabetic knowledge gained from either reading an alphabetic orthography or special training.

Alphabetic knowledge also facilitates Chinese speakers' PA in Mandarin. One written Chinese, which is Mandarin-based in phonology and logographic in orthography, is used by speakers of different Chinese varieties. Elementary children in Mainland China and Taiwan are taught to read Chinese characters using different phonetic systems, Pinyin or Zhuyin fuhao, respectively (Huang \& Hanley, 1997). Cantonese-speaking children in Hong Kong are taught the sounds of Cantonese through a look and say method rather than an alphabetic script like Pinyin (Cheung, 2003; Ho \& Bryant, 1997; Holm \& Dodd, 1996; McBride-Chang, Bialystok, Chong \& Li, 2004). Therefore, they are less sensitive to intraword phonological structures than children in Mainland China and Taiwan.

A large body of research has been conducted to explore the effects of the alphabetic knowledge based on Pinyin or Zhuyin fuhao on Chinese speakers' PA in Mandarin by comparing preliterate and beginning students (Huang \& Hanley, 1997; Ren, Xu, \& Zhang, 2005), children with and without alphabetic training (McBride-Chang et al., 2004) and adults with and without alphabetic knowledge (Read, Zhang, Nie \& Ding, 1986). These studies have revealed no or little, if any, effect of Pinyin or Zhuyin fuhao learning on syllable and rhyme awareness, but a definitive positive effect on phoneme awareness, consistent with the conclusion of Morais et al. (1987) that the development of phoneme awareness results not from literacy in general, but from alphabetic literacy in specific.

In the research field of PA in L2 English, there is growing interest in exploring the effect of L1 alphabetic knowledge on PA in English. The rationale is Cummins' (1980, p. 179) theory of "linguistic interdependence", which postulates that the developments of L1 and L2 proficiency are interdependent, with the former accounting partially for the latter. L1 and L2 manifest the same underlying processing system, so previous learning experience in L1 will predict future learning of L2 (if there is sufficient exposure to L2). For L2 learners, PA in their L2 can be affected by the phonology and orthography of their L1 through cross-language transfer. Evidence has accumulated from studies on L2 learners of English speaking other alphabetic languages, such as Spanish (Durgunoglu, Nagy \& Hancin-Bhatt, 1993), French (Comeau, Cormier, Grandmaison \& Lacroix, 1999), Punjabi (Chiappe \& Siegel, 1999) and Portuguese (DaFontoura \& Siegel, 1995). Cross-language transfer has also been found between languages different in orthography.

In terms of Chinese English learners, some studies have established a significant correlation between PA in Mandarin and PA in English for either younger participants or adults outside Mainland China (Chien, Kao \& Wei, 2008; Gottardo, Chiappe, Yan, Siegel \& Gu, 2006; Luo, Chen \& Geva, 2014; Nguyen-hoan \& Taft, 2010). Other studies have investigated whether PA in Mandarin facilitates or hinders PA in L2 English. One line of evidence emerges from comparative studies in which Mandarin-speaking children or adults attained significantly better performances on English PA tasks than Cantonese-speaking ones because the latter group, as discussed above, lacked Pinyin alphabetic literacy (Holm \& Dodd, 1996; Leong, Cheng \& Tan, 2005; Mcbride-Chang et al., 2004). Another line of evidence comes from the developmental research which focused on PA development in English of L2 child learners in Mainland China. The results indicated that learners' PA in Mandarin facilitated all three levels of PA in English, suggesting a strong facilitative role of Pinyin alphabetic knowledge in PA in L2 English (Ren, Xu, \& Zhang, 2005; Xu \& Dong, 2005).

Compared with Chinese children, Chinese college students in Mainland China are under-researched. Among insufficient studies on college English learners (Pan, 2012; Pan \& Gai, 2013; Tang, 2009; Wu, 2012), none explored the impact of mixed language experience on college students' PA in English. Given the gap in previous research, this study focuses on the aforesaid two kinds of language experience relevant to Chinese college learners — early spoken language and Pinyin alphabetic knowledge - to investigate their roles in Chinese adult learners' PA in English.

\section{METHOD}

\section{A. Participants}

The participants were 408 non-English majors from a key university in Mainland China (average age $=20.4$ ), all in the second semester of their second year and voluntarily participating in this study. They were all Chinese speakers; they had learned English for at least seven years since middle school and were assigned to intermediate classes by an English placement test administered upon their entry into university. They were coded in accordance with the two kinds of language experience:

1) Their early spoken language was operationalized by the participants' home language gathered from a questionnaire (see Appendix 1 for the translated English version). Those who spoke Mandarin or Mandarin dialects were included in the Mandarin group; those who spoke other dialects were in the dialect group.

2) Their Pinyin alphabetic knowledge was operationalzied by the participants' scores on the Mandarin PA test.

\section{B. Design and Materials}


Two audio tests were created based on previous research (Hu, 2012; Stahl \& Murray, 1994; Yopp, 1988): The Mandarin PA test was designed to assess the participants' Pinyin alphabetic knowledge and the English PA test their PA in English. To control for the word frequency, all items in both tests were non-words constructed based on the phonological rules of either Mandarin or English. Test items were recorded respectively by one native speaker of Mandarin and that of British English with the Cool Edit Pro software and then converted to mp3 files. The participants were given five seconds to respond to each item.

Mandarin PA test. We employed four tasks based on the unique phonological characteristics of Mandarin, one for a specific phonological unit. Syllable differentiation (20 items) asked the participants to determine whether two syllables in a pair of bi-syllabic words with the first tone were the same or different. For example, /bāsūi/ and /bālōu/ has the same first syllable /bā/. Onset oddity (20 items) asked the participants to detect the one with a different onset from three monosyllabic words with the same tone. For example, among /nōu/, /niāo/ and /biū/, /biū/ is the odd one. Rhyme oddity (20 items) asked the participants to judge which word had a different rhyme from three monosyllabic words with the same tone. For example, among /qōu/,/rō/ and /q̄ō/, the odd one is /qōu/. Tone identification (24 items) asked the participants to identify the tone of a monosyllabic word. For example, /déi/ has the second tone.

English PA test. We constructed 12 subtests (see Table I) of ten items each to examine PA in English across three levels of phonological units (syllable, onset-rhyme and phoneme) and four processing skills or tasks (oddity, segmentation, blending and substitution). The four tasks assessing the same level of PA adopted items with identical syllabic structures. The items included linguistically different sounds such as sibilants, palatals or labiodentals. To distinguish between the onset and first phoneme, we only used words with double-phoneme onsets (e.g., /plid/) to assess phoneme awareness.

TABLE I.

THE ENGLISH PA TEST AND ITS ITEM COMPOSITION B Y LEVEL OF PA AND TASK (C=CONSONANT, V=VOWEL)

\begin{tabular}{|c|c|c|c|c|}
\hline \multirow{2}{*}{ Level of PA } & \multicolumn{4}{|l|}{ Task } \\
\hline & Oddity & Segmentation & Blending & Substitution \\
\hline Syllable & $\begin{array}{l}\text { /bi'kっk/_/tæ'saik/_/tæ'met/ } \\
\text { CV/CVC }\end{array}$ & $\begin{array}{l}\text { /fə'len/_/fə/+/len/ } \\
\text { CV/CVC }\end{array}$ & $\begin{array}{l}\text { /gi/+/sæl/_/gi'sæl/ } \\
\text { CV/CVC }\end{array}$ & $\begin{array}{l}\text { /mə'pil/_/nə'pil/ } \\
\text { CV/CVC }\end{array}$ \\
\hline Onset-rhyme & $\begin{array}{l}\text { /3ik/_/tæl/_/zed/ (onset) } \\
/ \text { / ed/_/yed/_/gen/ (rhyme) } \\
\text { CVC }\end{array}$ & $\begin{array}{l}\text { /baim/_-/b/+/aim/ } \\
\text { CVC }\end{array}$ & $\begin{array}{l}\text { /g/+/æk/—/gæk/ } \\
\text { CVC }\end{array}$ & $\begin{array}{l}\text { /faig/_/gaig/ (onset) } \\
\text { /ð3:t/_/ðəug/ (rhyme) } \\
\text { CVC }\end{array}$ \\
\hline Phoneme & $\begin{array}{l}\text { /plaid/_/pli:m/__/brau } \theta / \\
\text { CCVC }\end{array}$ & $\begin{array}{l}\text { /smeid/- /s/+/m/+/ei/+/d/ } \\
\text { CCVC }\end{array}$ & $\begin{array}{l}/ \mathrm{b} /+/ \mathrm{l} /+/ \mathrm{e} /+/ \mathrm{p} /-/ \mathrm{blep} / \\
\mathrm{CCVC}\end{array}$ & $\begin{array}{l}\text { /snoig/_/broig/ } \\
\text { CCVC }\end{array}$ \\
\hline
\end{tabular}

\section{Procedure}

The participants were divided into three groups at random with approximately 130 students in each guided by a different experimenter. For the Mandarin PA test, all three groups were tested simultaneously in separate computerized classrooms. The experimenter first handed out an answer sheet with a questionnaire in Chinese (see Appendix 1 for the English version) and asked the participants to answer the questionnaire regarding their demographic information and home language. Prior to each task, the experimenter provided brief instructions, two demonstration items and three practice items with correct answers. Then the experimenter played the mp3 files with test items over two loudspeakers, using the Windows Media Player on the classroom computer. The participants wrote down their answers on the answer sheet after listening to each item. The entire testing session lasted approximately 40 minutes.

The English PA test, starting one week later, required oral production and thus was administered on a one-on-one basis. The experimenter of each group tested one participant at a time in a quiet office. Prior to each subtest, the experimenter provided brief instructions, two demonstration items and three practice items with correct answers. Then the experimenter played the mp3 files with test items using the Window Media Player on the office desktop and required the participant to provide a verbal answer to each item. The answers were recorded with a Philips VTR5000 voice recorder. Each testing session lasted for 40 minutes or so and the whole data collection for approximately one month.

\section{RESULTS}

The data consisted of each participant's scores on both the Mandarin and English PA tests. For the Mandarin test, a participant's scores of all four tasks were summed up for his/her Pinyin alphabetic knowledge. For the English test, scores were calculated by four sets as four dependent variables: 1) a composite of scores on all 12 subtests as overall PA, 2) scores across three levels of PA, 3) scores across four tasks and 4) scores of 12 subtests. One-way ANOVAs were carried out to analyze the main effects of early spoken language on the above four dependent variables; correlation tests were performed to assess the relationship between Mandarin PA test scores and the four sets of English PA test scores and one-way linear regressions the predictive effects of the former on the latter.

\section{A. Early Spoken Language}


As Table II shows, early spoken language had a significant effect on overall PA $(F=7.868 ; p=.005)$ : The dialect group $(M=73.30)$ outscored the Mandarin group $(M=70.66)$. On the level of PA, the dialect group outperformed the Mandarin group, but the two groups did not differ significantly from each other in syllable awareness $(p=.091)$. On the four tasks (processing skills), the dialect group performed better than the Mandarin group, but a significant effect held merely for blending and substitution. On the 12 subtests (shown in Table III), a significant effect was found for three ones: onset-rhyme oddity $(p=.007)$, phoneme blending $(p=.000)$ and syllable substitution $(p=.008)$.

TABLE II.

MEANS AND STANDARD ERRORS BY OVERALL PA, LEVEL OF PA AND TASK

\begin{tabular}{|c|c|c|c|c|c|c|c|c|}
\hline \multirow[b]{2}{*}{ Subjects } & \multirow[b]{2}{*}{$\begin{array}{l}\text { Overall } \\
\text { PA }\end{array}$} & \multicolumn{3}{|c|}{ Level of PA } & \multicolumn{4}{|l|}{ Task } \\
\hline & & Syllable & Onset-rhyme & Phoneme & Oddity & Segmentation & Blending & $\begin{array}{l}\text { Substitut } \\
\text { on }\end{array}$ \\
\hline $\begin{array}{l}\text { Total } \\
n=408\end{array}$ & $\begin{array}{l}71.76 \\
(0.47) \\
\end{array}$ & $\begin{array}{l}26.33 \\
(0.19) \\
\end{array}$ & $\begin{array}{l}24.31 \\
(0.22) \\
\end{array}$ & $\begin{array}{l}21.11 \\
(0.16) \\
\end{array}$ & $\begin{array}{l}25.90 \\
(0.11) \\
\end{array}$ & $\begin{array}{l}22.14 \\
(0.18) \\
\end{array}$ & $\begin{array}{l}9.90 \\
(0.18) \\
\end{array}$ & $\begin{array}{l}13.83 \\
(0.19) \\
\end{array}$ \\
\hline $\begin{array}{l}\text { Mandarin } \\
\text { group } \\
n=239\end{array}$ & $\begin{array}{l}70.66 \\
(0.62)\end{array}$ & $\begin{array}{l}26.05 \\
(0.26)\end{array}$ & $\begin{array}{l}23.88 \\
(0.28)\end{array}$ & $\begin{array}{l}20.72 \\
(0.21)\end{array}$ & $\begin{array}{l}25.72 \\
(0.15)\end{array}$ & $\begin{array}{l}21.98 \\
(0.25)\end{array}$ & $\begin{array}{l}9.53 \\
(0.22)\end{array}$ & $\begin{array}{l}13.46 \\
(0.25)\end{array}$ \\
\hline \multirow[t]{2}{*}{$\begin{array}{l}\text { Dialect group } \\
n=169\end{array}$} & $\begin{array}{l}73.30 \\
(0.69)\end{array}$ & $\begin{array}{l}26.72 \\
(0.28)\end{array}$ & $\begin{array}{l}24.91 \\
(0.34)\end{array}$ & $\begin{array}{l}21.67 \\
(0.25)\end{array}$ & $\begin{array}{l}26.16 \\
(0.15)\end{array}$ & $\begin{array}{l}22.37 \\
(0.25)\end{array}$ & $\begin{array}{l}10.42 \\
(0.30)\end{array}$ & $\begin{array}{l}14.34 \\
(0.29)\end{array}$ \\
\hline & $\begin{array}{l}F=7.868 \\
p=.005\end{array}$ & $\begin{array}{l}F=3.873 \\
p=.091\end{array}$ & $\begin{array}{l}F=5.487 \\
p=.02\end{array}$ & $\begin{array}{l}F=8.178 \\
p=.004\end{array}$ & $\begin{array}{l}F=4.134 \\
p=.043\end{array}$ & $\begin{array}{l}F=1.137 \\
p=.287\end{array}$ & $\begin{array}{l}F=5.894 \\
p=.016\end{array}$ & $\begin{array}{l}F=5.308 \\
p=.022\end{array}$ \\
\hline
\end{tabular}

TABLE III.

MEANS AND STANDARD ERRORS BY SUBTEST

\begin{tabular}{|c|c|c|c|c|c|c|c|c|c|c|c|c|}
\hline \multirow[b]{2}{*}{ Subjects } & \multicolumn{3}{|l|}{ Oddity } & \multicolumn{3}{|c|}{ Segmentation } & \multicolumn{3}{|l|}{ Blending } & \multicolumn{3}{|c|}{ Substitution } \\
\hline & Syllable & $\begin{array}{l}\text { Onset- } \\
\text { rhyme }\end{array}$ & Phoneme & Syllable & $\begin{array}{l}\text { Onset- } \\
\text { rhyme }\end{array}$ & Phoneme & Syllable & $\begin{array}{l}\text { Onset- } \\
\text { rhyme }\end{array}$ & Phoneme & Syllable & $\begin{array}{l}\text { Onset- } \\
\text { rhyme }\end{array}$ & Phoneme \\
\hline Total & 9.53 & 9.11 & 7.26 & 7.13 & 8.36 & 6.65 & 4.05 & 2.98 & 2.88 & 5.65 & 3.86 & 4.32 \\
\hline$n=408$ & $(0.43)$ & $(0.05)$ & $(0.07)$ & $(0.09)$ & $(0.10)$ & $(0.07)$ & $(0.08)$ & $(0.08)$ & $(0.07)$ & $(0.09)$ & $(0.10)$ & $(0.07)$ \\
\hline Mandarin group & 9.51 & 9.00 & 7.22 & 7.11 & 8.27 & 6.59 & 4.03 & 2.87 & 2.64 & 5.44 & 3.74 & 4.27 \\
\hline$n=239$ & $(0.06)$ & $(0.07)$ & $(0.09)$ & $(0.13)$ & $(0.14)$ & $(0.10)$ & $(0.11)$ & $(0.10)$ & $(0.09)$ & $(0.12)$ & $(0.12)$ & $(0.09)$ \\
\hline \multirow{4}{*}{$\begin{array}{l}\text { Dialect group } \\
n=169\end{array}$} & 9.56 & 9.27 & 7.33 & 7.14 & 8.49 & 6.73 & 4.07 & 3.13 & 3.23 & 5.95 & 4.03 & 4.38 \\
\hline & $(0.06)$ & $(0.07)$ & $(0.10)$ & $(0.14)$ & $(0.15)$ & $(0.09)$ & $(0.12)$ & $(0.14)$ & $(0.13)$ & $(0.14)$ & $(0.15)$ & $(0.11)$ \\
\hline & $F=0.351$ & $F=7.251$ & $F=0.741$ & $F=0.023$ & $F=1.055$ & $F=0.846$ & $F=0.061$ & $F=2.316$ & $F=14.741$ & $F=7.091$ & $F=2.185$ & $F=0.586$ \\
\hline & $p=.554$ & $p=.007$ & $p=.390$ & $p=.879$ & $p=.305$ & $p=.358$ & $p=.805$ & $p=.129$ & $p=.000$ & $p=.008$ & $p=.140$ & $p=.444$ \\
\hline
\end{tabular}

\section{B. Pinyin Alphabetic Knowledge}

A full correlation matrix for all of the variables is given in Tables IV and V. It is clear from Table 4 that Pinyin alphabetic knowledge was significantly correlated with overall PA $(r=.25, p<.01)$. There were significant correlations between Pinyin and all three levels of PA ( $r=.23$ for syllable, .19 for onset-rhyme and .20 for phoneme). In terms of task, Pinyin had the strongest correlation with substitution $(r=.23, p<.01)$, similar correlations with oddity $(r=.15, p$ $<.01)$ and blending $(r=.16, p<.01)$ and the weakest one with segmentation $(r=.12, p<.05)$. Among 12 subtests (see Table 5), no significant correlations existed between Pinyin and phoneme oddity $(r=.04)$, onset-rhyme segmentation $(r$ $=.09)$ and phoneme segmentation $(r=.03)$. A weak correlation existed between Pinyin and syllable segmentation $(r$ $=.11)$, syllable blending $(r=.10)$ and onset-rhyme blending $(r=.11)$. A comparatively stronger correlation held for syllable oddity $(r=.16)$, onset-rhyme oddity $(r=.13)$, phoneme blending $(r=.14)$, syllable substitution $(r=.13)$, onset-rhyme substitution $(r=.17)$ and phoneme substitution $(r=.24)$. Taken together, the correlations between PA in Mandarin and four sets of scores on English PA were weak.

TABLE IV.

CORRELATIONS BETWEEN PINYIN SCORES AND ENGLISH PA TEST SCORES By OVERALl PA, LEVEL OF PA AND TASK

\begin{tabular}{|c|c|c|c|c|c|c|c|c|}
\hline & \multirow{2}{*}{$\begin{array}{l}\text { Overall } \\
\text { PA }\end{array}$} & \multicolumn{3}{|c|}{ Level of PA } & \multicolumn{4}{|l|}{ Task } \\
\hline & & syllable & $\begin{array}{l}\text { Onset- } \\
\text { rhyme }\end{array}$ & Phoneme & Oddity & Segmentation & Blending & Substitution \\
\hline Pinyin & $.25 * *$ & $.23 * *$ & $.19 * *$ & $.20 * *$ & $.15 * *$ & $.12 *$ & $.16^{* * *}$ & $.23 * *$ \\
\hline
\end{tabular}


TABLE V.

CORRELATIONS BETWEEN PINYIN SCORES AND ENGLISH PA TEST SCORES BY SUBTEST

\begin{tabular}{|c|c|c|c|c|c|c|c|c|c|c|c|c|}
\hline & \multicolumn{3}{|l|}{ Oddity } & \multicolumn{3}{|c|}{ Segmentation } & \multicolumn{3}{|l|}{ Blending } & \multicolumn{3}{|c|}{ Substitution } \\
\hline & Syllable & $\begin{array}{l}\text { Onset- } \\
\text { rhyme }\end{array}$ & $\begin{array}{l}\text { Pho- } \\
\text { neme }\end{array}$ & Syllable & $\begin{array}{l}\text { Onset- } \\
\text { rhyme }\end{array}$ & $\begin{array}{l}\text { Pho- } \\
\text { neme }\end{array}$ & Syllable & $\begin{array}{l}\text { Onset- } \\
\text { rhyme }\end{array}$ & $\begin{array}{l}\text { Pho- } \\
\text { neme }\end{array}$ & Syllable & $\begin{array}{l}\text { Onset- } \\
\text { rhyme }\end{array}$ & $\begin{array}{l}\text { Pho- } \\
\text { neme }\end{array}$ \\
\hline Pinyin & $.16^{* * *}$ & $.13 * *$ & .04 & $.11 *$ & .09 & .03 & $.10 *$ & $.11 *$ & $.14 * *$ & $.13 * *$ & $.17 * *$ & $.24 * *$ \\
\hline
\end{tabular}

The results from regression analyses are shown in Table VI. Pinyin significantly predicted overall PA $(p=.000)$ but accounted for merely $6 \%$ of the variance. Pinyin also significantly predicted all three levels of PA (all $p=.000)$, but only accounted for $5.1 \%$ of the variance for syllable, $3.5 \%$ for onset-rhyme and $3.7 \%$ for phoneme. Among the four tasks, Pinyin predicted substitution the most $\left(R^{2}=0.052, p=.000\right)$, approximately $2 \%$ for both blending $\left(R^{2}=0.024, p\right.$ $=.002)$ and oddity $\left(R^{2}=0.019, p=.000\right)$ and segmentation $\left(R^{2}=0.014, p=.018\right)$ the least. Among the 12 subtests, Pinyin failed to significantly predict phoneme oddity $\left(R^{2}=0.002, p=.391\right)$ for oddity; so did Pinyin two of the three segmentation subtests: onset-rhyme segmentation $\left(R^{2}=0.008, p=.076\right)$ and phoneme segmentation $\left(R^{2}=0.001, p\right.$ $=.494)$. Pinyin significantly predicted all blending and substitution subtests, but explained more variance for substitution (ranging from $1.8 \%$ to $5.7 \%$ ) than for blending (ranging from $1.1 \%$ to $2 \%$ ). Echoing the results of correlation analyses, Pinyin was a significant but weak predictor of PA in English.

TABLE VI

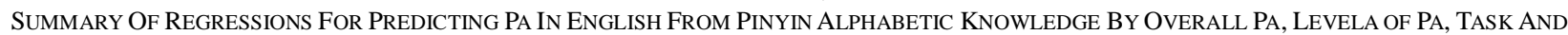
SUBTEST

\begin{tabular}{|c|c|c|c|c|c|c|c|c|}
\hline \multicolumn{9}{|c|}{ SUBTEST } \\
\hline & & & $B$ & $\beta$ & $t$ & $R^{2}$ & $F$ & $p$ \\
\hline Overall & & & .317 & .250 & 5.192 & .060 & 26.961 & $.000 * * *$ \\
\hline \multirow{3}{*}{\multicolumn{2}{|c|}{ Level o PA }} & Syllable & .118 & .226 & 4.671 & .051 & 21.818 & $.000 * * *$ \\
\hline & & Onset-rhyme & .110 & .186 & 3.820 & .035 & 14.591 & $.000 * * *$ \\
\hline & & Phoneme & .088 & .197 & 4.058 & .037 & 16.471 & $.000 * * *$ \\
\hline \multirow{4}{*}{\multicolumn{2}{|c|}{ Task }} & Oddity & .043 & .148 & 3.010 & .019 & 9.060 & $.003 * *$ \\
\hline & & Segmentation & .057 & .117 & 2.383 & .014 & 5.680 & $.018^{*}$ \\
\hline & & Blending & .077 & .155 & 3.159 & .024 & 9.982 & $.002 * *$ \\
\hline & & Substitution & .120 & .233 & 4.817 & .052 & 23.201 & $.000^{*} * *$ \\
\hline \multirow{12}{*}{ Subtest } & \multirow{3}{*}{ Oddity } & Syllable & .019 & .160 & 3.263 & .026 & 10.645 & $.001 * *$ \\
\hline & & Onset-rhyme & .017 & .128 & 2.598 & .016 & 6.749 & $.010^{*}$ \\
\hline & & Phoneme & .008 & .043 & .860 & .002 & .739 & .391 \\
\hline & \multirow{3}{*}{ Segmentation } & Syllable & .027 & .107 & 2.171 & .011 & 4.713 & $.031^{*}$ \\
\hline & & Onset-rhyme & .025 & .088 & 1.777 & .008 & 3.158 & .076 \\
\hline & & Phoneme & .007 & .034 & .685 & .001 & .469 & .494 \\
\hline & \multirow{3}{*}{ Blending } & Syllable & .023 & .103 & 2.085 & .011 & 4.346 & $.038 *$ \\
\hline & & Onset-rhyme & .025 & .110 & 2.235 & .012 & 4.994 & $.026^{*}$ \\
\hline & & Phoneme & .029 & .141 & 2.861 & .020 & 8.183 & $.004 * *$ \\
\hline & \multirow{3}{*}{ Substitution } & Syllable & .034 & .134 & 2.725 & .018 & 7.426 & $.007 * *$ \\
\hline & & Onset-rhyme & .043 & .166 & 3.391 & .028 & 11.499 & $.001 * *$ \\
\hline & & Phoneme & .045 & .239 & 4.953 & .057 & 24.528 & $.000 * * *$ \\
\hline
\end{tabular}

\section{DISCUSSION}

\section{A. Early Spoken Language and English PA Performance}

The dialect group performed better on all measures than the Mandarin group, suggesting an advantage of dialect. This result replicates the finding with speakers of different languages (e.g., Caravolas \& Bruck, 1993; Cheung et al., 2001; Cossu et al., 1988), confirming an influence of early spoken language on PA performance. This result, along with previous research on PA in Mandarin (Lin et al., 2009; Wang, 2006), indicates that speaking a dialect does not hinder Chinese speakers' PA in either Mandarin or English. The ability to speak more than one variety of language enhances PA because multi-language experience offers children "contrastive linguistic instruction" which enables them to compare and segment phonological structures of a language better than monolingual children (Bruck \& Genesee, 1995 , p. 307). The current study reveals that the positive impact of dialect also holds for adult participants.

It is worth noticing that early spoken language failed to significantly affect oddity and segmentation which outscored blending and substitution as well as syllable awareness which scored higher than onset-rhyme and phoneme awareness (see Table II). Zhu (2014) found that bi-dialectal children outperformed Mandarin monolinguals on the difficult task, but not on the easy one. The findings of the current study extend the Zhu (2014) study by demonstrating that the effect of dialect hinges on both task and level of PA. Tasks with higher difficulty or awareness of smaller phonological units (e.g., phoneme) require more explicit perceptive and analytic skills, thus entailing more aid from facilitative factors such as dialect.

The above findings may explain why dialect significantly affected phoneme blending among 12 subtests where both level of PA and task interplay. Phoneme is the smallest phonological unit and blending scored the lowest among four tasks. However, it does not explain why dialect also significantly affected the other two subtests: syllable substitution 
and onset-rhyme oddity which scored comparatively higher than other tests. Therefore, the findings may be random and more research is needed on how level of PA and task (processing skill) interact with each other to affect the role of dialect in English PA.

\section{B. Pinyin Alphabetic Knowledge and English PA Performance}

Pinyin alphabetic knowledge was shown to be a significant predictor of PA in English, thus lending more support to Cummin's (1980) theory of L1-L2 interdependence. The result replicates the finding of previous research on both children (Chien et al., 2008; Ren et al., 2005; Xu \& Dong, 2005) and adults (Holm \& Dodd, 1996), suggesting transferability of decoding skills from L1 to L2 regardless of difference in orthography. The phonological structure of Pinyin is simpler than that of English. There are four syllable structures in Mandarin: V, CV, VC and CVC (Li \& Thompson, 1981). The two final consonants, /n/ and /ng/, always go with vowels (e.g., /en/, /eng/, /in/, /ing/). The VC structure (say, /in/) is taught as one unit instead of a combination of one vowel /i/ and one consonant/n/. Mandarin has perfect grapheme-phoneme correspondence whereas English has a deep orthography (Chen, Xu, Nguyen, Hong \& Wang, 2010, p. 713). Despite these differences, consonants and rhymes in Pinyin are similar to those of English, syllable structures can find equivalents in English and tones may be deemed as equivalent to stress in English (Zhang \& Lin, 2002). These similarities may explain why phonological processing skills acquired in Mandarin can transfer to boost PA in English. Another plausible explanation could be the notion of Durgunoglu, Nagy and Hancin-Bhatt (1993, p. 462) that since similar underlying processing mechanisms are employed for PA in different languages, such "metalinguistic awareness need not be language specific".

The above finding complements previous studies on Chinese children (Chien et al., 2008; Ren et al., 2005; Xu \& Dong, 2005) by indicating that the transfer effect from PA in Mandarin to PA in English also holds for adult learners. Previous research on English L1 learners (e.g., Liberman et al., 1974; Yopp, 1988) has established that syllable awareness and rhyme awareness develop out of the impact of alphabetic knowledge. The current study, contrarily, yields the finding that the predictive effect of Pinyin occurred to all levels of PA, thus corroborating an impact of L1 alphabetic knowledge on L2 English PA. However, it cannot be ignored that either the correlations between Pinyin and English PA performance or the predictive effects of the former on the latter are rather weak compared with previous studies on Chinese child learners of English (Chien et al., 2008; Ren et al., 2005; Xu \& Dong, 2005). Could it be that the effect of L1 transfer declines with the improvement of English proficiency? The participants in the current study were adults in a key university who had been learning English for at least 7 years. As Corder (1979) maintains, L2 learners could use their L1 knowledge as a learner strategy to make up for their insufficient L2 knowledge. When they have difficulty communicating their ideas, they would borrow from their L1. Hence, L2 learners resort more to their L1 at the earlier learning stage than later.

In addition, the measures which Pinyin failed to significantly predict include one oddity subtest, two segmentation subtests and none of blending and substitution subtests. This result confirms Lewkowicz's (1980) proposal that a precise assessment of PA should be conducted across both level of PA and task (processing skill). Most of previous studies (e.g., Chien et al, 2008; Pan, 2012), nonetheless, tested three levels of PA using dissimilar tasks, thus ignoring differential effects of the same task on different levels of PA. Our study, on the contrary, designed the same four tasks for each level of PA; therefore, the aforesaid result points to the interplay of language experience with difficulty of task. Further analyses indicated that these four tasks (see Table 2) were ranked, according to the difficulty level measured by mean scores, as oddity $(25.90)$ < segmentation $(22.14)<$ substitution $(13.83)<$ blending $(9.90)$. It follows that the predictive effect of Pinyin might vary with the difficulty of these tasks. This finding can explain why Pinyin scores did significantly predict all subtests for the most two difficult tasks (substitution and blending), but not all for the two easier tasks (oddity and substitution).

An interesting finding is that Pinyin had the closest relationship with syllable awareness, but previous research (e.g., Bryant et al., 1990) showed almost no relationship between PA and syllable awareness of native speakers. In terms of Chinese speakers, research (e.g., Gottardo et al., 2006; Xu \& Dong, 2005) revealed mixed results. A possible explanation, as Bialystok, McBride-Chang and Luk (2005) argue, is that what and how much transfers from L1 to L2 depend on the L1/L2 pair. Based on this theory, the phonological structure of Pinyin is typical of syllable combinations; this language-specific pattern in Mandarin may cause Chinese speakers to develop a strong syllable awareness which can be transferred to boost the same PA skill in their L2 English.

With both kinds of language experience considered, the results manifest that PA in English was facilitated by both dialect and Pinyin Alphabetic knowledge. Learning Pinyin shapes decoding skills PA requires whereas speaking more dialects enhances such skills. PA in English is directly related to a command of intraword structures acquired through alphabetic literacy or special training specific to English. Its shortage can be offset by higher English proficiency which promotes such a command, though. If English proficiency is insufficient, L1 alphabetic knowledge entrenched in Chinese students will transfer to help L2 learners' PA performance. If English proficiency is sufficient, conversely, this transfer effect from L1 will atrophy as happened in our study. Taken together, these two variables are conducive but not essential to Chinese college students' PA in English.

\section{CONCLUSION}


The current study has found that two kinds of language experience played an important part in Chinese college students' PA in English and that their effects were mediated by level of PA and difficulty of task. Theoretically, these findings add to our understanding in two aspects. For one thing, PA performance in L2 results from mixed factors involving either L2 or L1 learning experience, which should not be separately examined. For another, effects of a factor vary with both the processing skill of a task and the phonological level the task measures. This study thus suggests the necessity for researchers to assess all levels of PA across various tasks to gain a complete and more accurate understanding of PA skills.

This study has also demonstrated that L1 language experience, be it dialect or Pinyin alphabetic knowledge, boosted Chinese learners' English PA even in adulthood. Pedagogically, the finding provides insights for Chinese English teachers at different stages, esp. at college level, to develop PA teaching programs, which highlight the GPC rule in English and meanwhile take Chinese experience into consideration by clarifying the similarities in phonology between these two languages to trigger a positive transfer. Such programs also need to consider level of PA and difficulty of task to develop learners' PA across phonological unit and processing skill.

This study, nonetheless, has found weak transfer effects from Pinyin alphabetic knowledge which might be accounted for by the comparatively higher English proficiency of the adult participants. Therefore, future studies are called for to investigate how English proficiency would interact with L1 language experience to impact PA in English of Chinese English learners.

\section{APPENDIX}

Questionnaire in English-Please answer the following questions before the test:

1. Your age

2. Your home town ___ and home language

3. Other Chinese languages you can speak fluently

4. Years of learning English

\section{REFERENCES}

[1] Alegria, J., E. Pignot \& J. Morais. (1982). Phonetic analysis of speech and memory codes in beginning readers. Memory \& Cognition, 10, 451-456.

[2] Anthony, J. L. \& D. J. Francis. (2005). Development of phonological awareness. Current Directions in Psychological Science, $14,255-259$.

[3] Barton, D., R. Miller \& M. Macken. (1980). Do children treat clusters as one unit or two? Papers and Reports on Child Language Development, 18, 93-137.

[4] Bentin, S., R. Hammer \& S. Cahan. (1991). The effects of aging and first grade schooling on the development of phonological awareness. Psychological Science, 2, 271-274.

[5] Bialystok, E., C. McBride-Chang \& G. Luk. (2005). Bilingualism, language proficiency, and learning to read in two writing systems. Journal of Educational Psychology, 97, 580-590.

[6] Bowey, J. A. \& J. Franscis. (1991). Phonological analysis as a function of age and exposure to reading instruction. Applied Psycholinguistics, 12, 91-121.

[7] Bruce, D. J. (1964). An analysis of word sounds by young children. British Journal of Educational Psychology, 34, 158-170.

[8] Bruck, M. \& F. Genesee. (1995). Phonological awareness in young second language learners. Journal of Child Language, 22, 307-324.

[9] Bruck, M., F. Genesee \& M. Caravolas. (1997). A cross-linguistic study of early literacy acquisition. In B. A. Blachman (Ed.). Foundations of reading acquisition and dyslexia: Implications for early intervention. Mahwah, NJ: Lawrence Erlbaum, 145-162.

[10] Bryant, P., M. MacLean, L. Bradley \& J. Crossland. (1990). Rhyme and alliteration, phoneme detection, and learning to read. Developmental Psychology, 26, 429-438.

[11] Caravolas, M. \& M. Bruck. (1993). The effect of oral and written language input on children's phonological awareness: a cross-linguistic study. Journal of Experimental Child Psychology, 55, 1-30.

[12] Chen, X., R. C. Anderson, W. Li, M. Hao, X. Wu \& H. Shu. (2004). Phonological awareness of bilingual and monolingual Chinese children. Journal of Educational Psychology, 96, 142-151.

[13] Chen, X., F. Xu, T. K. Nguyen, G. L. Hong \& Y. Wang. (2010). Effects of cross-language transfer on first-Language phonological awareness and literacy skills in Chinese children receiving English instruction. Journal of Educational Psychology, 102, 712-728.

[14] Cheung, H. (2003). Pinyin and phonotactics affect the development of phonemic awareness in English-Cantonese bilinguals. In C. McBride-Chang \& H.-C. Chen (Eds.), Reading development in Chinese children. Westport, CT: Praeger Publishers, 229-239.

[15] Cheung, H., H. C. Chen, C. Y. Lai, O. C. Wong \& M. Hills. (2001). The development of phonological awareness: Effects of spoken language experience and orthography. Cognition, 81, 227-241.

[16] Chiappe, P. \& L. S. Siegel. (1999). Phonological awareness and reading acquisition in Enlgish- and Punjabi-speaking Canadian children. Journal of Educational Psychology, 91, 20-28.

[17] Chien, C.-N., L. H. Kao \& L. Wei. (2008). The role of phonological awareness development in young Chinese EFL learners. Language Awareness, 17, 271-288. 
[18] Comeau, L., P. Cormier, E. Grandmaison \& D. Lacroix. (1999). A longitudinal study of phonological processing skills in children learning to read in a second language. Journal of Educational Psychology, 91, 29-43.

[19] Corder, S. (1979). Language distance and the magnitude of the learning task. Studies in Second Language Acquisition, 2, $27-36$.

[20] Cossu, G., D. Shankweiler, I. Y. Liberman, L. E. Katz \& G. Tola. (1988). Awareness of phonological segments and reading ability in Italian children. Applied Psycholinguistics, 9, 1-16.

[21] Cummins, J. (1980). The cross-lingual dimensions of proficiency: Implications for bilingual education and the optimal age issue. TESOL Quarterly, 14, 175-187.

[22] DaFontoura, H. A. \& L. S. Siegel. (1995). Reading, syntactic and working memory skills of bilingual Portuguese-English Canadian children. Reading and Writing: An Interdisciplinary Journal, 7, 139-153.

[23] Demont, E. \& J. E. Gombert. (1996). Phonological awareness as a predictor of recoding skills and syntactic awareness as a predictor of comprehension skills. British Journal of Educational Psychology, 66, 315-332.

[24] Ding, Z.-P \& D. L. Peng. (1998). English phonological awareness of Chinese children and spelling. Acta Psychologica Sinica, $30,248-253$

[25] Durgunoglu, A., W. Nagy \& B. Hancin-Bhatt. (1993). Cross-language transfer of phonological awareness. Journal of Educational Psychology, 85, 453-465.

[26] Durgunoglu, A. Y. \& B. Oney. (1999). A cross-linguistic comparison of phonological awareness and word recognition. Reading \& Writing, 11, 281-299.

[27] Gillon, G. T. (2004). Phonological awareness: From research to practice. New York, NY: Guilford Press.

[28] Gorman, B. K. (2012). Relationships between vocabulary size, working memory, and phonological awareness in Spanish-speaking English language learners. American Journal of Speech-Language Pathology, 21, 109-123.

[29] Gottardo, A., P. Chiappe, B. Yan, L. Siegel \& Y. Gu. (2006). Relationships between first and second language phonological processing skills and reading in Chinese-English speakers living in English-speaking contexts. Educational Psychology, 26, $367-393$

[30] Goswami, U. (1999). The relationship between phonological awareness and orthographic representation in different orthographies. In M. Harris, \& G. Hatano (Eds.), Learning to read and write: A cross-linguistic perspective. NY: Cambridge University Press, 134-156.

[31] Goswami, U. \& P. E. Bryant. (1990). Phonological skills and learning to read. London: Erlbaum.

[32] Ho, C. S. H. \& P. Bryant. (1997). Development of phonological awareness of Chinese children in Hong Kong. Journal of Psycholinguistic Research, 26, 109-126.

[33] Holm, A. \& B. Dodd. (1996). The effect of first written language on the acquisition of English literacy. Cognition, 59, 119-147.

[34] Hu, M. (2012). Phonological Awareness in Mandarin of Chinese and Americans. Shanghai: Shanghai Joint Publishing Press.

[35] Huang, H.-S. \& J. R. Hanley. (1997). A longitudinal study of phonological awareness, visual skills, and Chinese reading acquisition among first graders in Taiwan. International Journal of Behavioral Development, 20, 249-268.

[36] Kartal, G., N. Babür \& G. Erçetin. (2016). Training for phonological awareness in an orthographically transparent language in two different modalities. Reading \& Writing Quarterly, 32, 550-579.

[37] Leong, C. K., P. W. Cheng \& L. H. Tan. (2005). The role of sensitivity to rhymes, phonemes and tones in reading English and Chinese pseudowords. Reading and Writing: An Interdisciplinary Journal, 18, 1-26.

[38] Lewkowicz, N. K. 1980. Phonemic awareness training: What to teach and how to teach it. Journal of Educational Psychology, $72,686-700$.

[39] Li, R.-B., S. M. Chen, Y. K. Wang \& G. Z. Li. (2011). Children's phonological experience and their phonological awareness. FLC (Foreign Languages in China), 8, 36-43.

[40] Li, C. N. \& S. A. Thompson. (1981). Mandarin Chinese: A functional reference grammar. Berkeley, CA: University of California Press.

[41] Liberman, I. Y., D. Shankweiler, F. W. Fisher \& B. Carter. (1974). Explicit syllable and phoneme segmentation in the young children. Journal of Experimental Child Psychology, 18, 201-212.

[42] Liberman, I. Y., D. Shankweiler \& A. M. Liberman. (1989). The alphabetic principle and learning to read. In D. Shankweiler \& I. Y. Liberman (Eds.), Phonology and Reading Disability: Solving the Reading Puzzle. Research Monograph Series. Ann Arbor: University of Michigan Press, 1-33.

[43] Lin, Y.-H., L, Y, Wang, Q. Z. Qian \& J. J. Qiu. (2011). The influence of Shanghai dialect on preschool children's Chinese phonological awareness. Journal of Psychological Science, 34, 414-17.

[44] Liu, C.-B. (2011). On the effects of Putonghua's popularization on Chinese directs. Journal of Inner Mongolia Agricultural University (Social Science Edition), 13, 200-202.

[45] Luo, Y. C., X. Chen \& E. Geva. (2014). Concurrent and longitudinal cross-linguistic transfer of phonological awareness and morphological awareness in Chinese-English bilingual children. Written Language \& Literacy, 17, 89-115.

[46] Maclean, M., P. Bryant \& L. Bradley. (1987). Rhymes, nursery rhymes, and reading in early childhood. Merrill-Palmer Quarterly, 33, 255-281.

[47] Mann. V. A. (1991). Are we talking too narrow a view of the conditions for development of phonological awareness? In S. A. Brady \& D. P. Shankweiler (Eds.), Phonological processes in literacy: A tribute to Isabelle Y. Liberman. Hillsdale, NJ: Lawrence Erlbaum, 55-64.

[48] McBride-Chang, C., E. Bialystok, K. K. Y. Chong \& Y. Li. (2004). Levels of phonological awareness in three cultures, Journal of Experimental Child Psychology, 89, 93-111.

[49] Morais, J., J. Alegria \& A. Content. (1987). The relationship between segmental analysis and alphabetic literacy. Cahiers de Psychologie Cognitive, 7, 415-438.

[50] Morais. J., P. Bertelson, L. Cary \& J. Alegria. (1986). Literacy training and speech segmentation. Cognition, 24, 45-64.

[51] Morais, J., L. Cary, J. Alegria \& P. Bertelson. (1979). Does awareness of speech as a sequence of phones arise spontaneously? Cognition, 7, 323-331. 
[52] Nguyen-hoan, M. \& M. Taft. (2010). The impact of a subordinate L1 on L2 auditory processing in adult bilinguals. Bilingualism: Language and Cognition, 13, 217-230.

[53] Pan, Y. (2012). Characteristics of mandarin-speaking students' English phonological processing development. Foreign Languages and Their Teaching, 6, 17-21.

[54] Pan, Y. \& X. S. Gai. (2013). A comparison of the developing trends of English phonological awareness between Mandarin-speaking students and English-speaking students. Studies of Psychology and Behavior, 11, 73-77.

[55] Read, C., Y. Zhang, H. Nie \& B. Ding. (1986). The ability to manipulate speech sounds depends on knowing alphabetic spelling. Cognition, 24, 31-44.

[56] Ren, P., F. Xu \& J. Yang. (2005). The effects of early language learning experience on the development of phonological awareness: A critical survey. Contemporary Linguistics, 4, 385-363.

[57] Sodoro, J., R. Allinder \& J. Rankin-Erickson. (2002). Assessment of phonological awareness: Review of methods and tools. Educational Psychology Review, 3, 223-260.

[58] Stahl, S. A. \& B. A. Murray. (1994). Defining phonological awareness and its relationship to early reading. Journal of Educational Psychology, 86, 221-34.

[59] Stanovich, K. E. (1992). Speculations on the causes and consequences of individual differences in early reading acquisition. In P. Gough, L. Ehri \& R. Treiman (Eds.), Reading acquisition. Hillsdale, NJ: Erlbaum, 307-342.

[60] Stanovich, K. E., A. E. Cunningham \& B. Cramer. (1984). Assessing phonological awareness in kindergarten children: Issues of task comparability. Journal of Experimental Child Psychology, 38, 175-190.

[61] Sun, Chaofen. (2006). Chinese: A linguistic introduction. Cambridge, NY: Cambridge Univ. Press.

[62] Tang, L. (2009). The correlation between phonological awareness and reading ability of adult Chinese EFL learners. Unpublished master's thesis. Chongqing University, Chongqing, China.

[63] Treiman, R. \& J. Baron. (1981). Segmental analysis ability: Development and relationship to reading ability. In G. E. MacKinnon, \& T. G. Waller (Eds.), Reading research: Advances in theory and practice, Vol. 3. NY: Academic Press, 159-198.

[64] Treiman, R. \& A. Zukowski. (1991). Levels of phonological awareness. In S. A. Brady \& D. P. Shankweiler (Eds), Phonological processes in literacy: A tribute to Isabelle Y. Liberman. Hillsdale, NJ: Lawrence Erlbaum, 67-83.

[65] Treiman. R. \& A. Zukowski. (1996). Children's sensitivity to syllables, onsets. rimes, and phonemes. Journal of Experimental Child Psychology, 61, 193-215.

[66] Wang, F.-F. (2010). A Study of the relation between phonological awareness and reading comprehension ability. Journal of Jinhua Polytechnic, 10, 26-30.

[67] Wang, Y.-K. (2004). Effects of dialects on children's development of phonological awareness. Unpublished master's thesis. Fujian Normal University, Fuzhou, Fujian, China.

[68] Wu, X.-F. (2012). English phonological awareness of college students of science and engineering. Journal of Shanxi Finance and Economics University, 34, 42.

[69] Xu, F. \& Q. Dong. (2005). Research on the relationship between development of Chinese and English phonological awareness in primary school. Psychological Development and Education, 1, 31-35.

[70] Xu, Y. (2015). College Students' Chinese Phonological Experience and English Phonological Awareness. Journal of Chengdu Normal University, 32, 16-19.

[71] Yopp, H. K. (1988). The validity and reliability of phonetic awareness tests. Reading Research Quarterly, 23, 159-177.

[72] Zhang, J.-J \& Z. H. Lin. (2002). Relationships between the level of Pinyin and the English phonetic awareness and spelling ability. Psychological Science, 25, 601-602.

[73] Zhu, Q.-Y. (2014). Effects of Chinese Dialects on English Phonological Awareness. Course Education Research, 3, 129.

Min Hu is an Associate Professor of English at the School of Foreign Languages, Southwest University of Political Science \& Law, China. She obtained her Ph.D. degree in English from Auburn University, USA. She specializes in second language acquisition and teaching English as a foreign language. 